\title{
Esthetic Evaluation of Maxillary Anterior Immediate Implant with Provisionalization with or without Bone Grafting
}

\author{
Neha Bhutani ${ }^{1}$, Ghousia Fatima ${ }^{2}$, Neha Rampure ${ }^{3}$, Roopali Tapashetti ${ }^{4}$, Sandeep S Prabhu ${ }^{5}$, Fatru Rahman ${ }^{6}$
}

\begin{abstract}
Aim: Immediate implant in the esthetic zone is a treatment of choice. However, much research regarding immediate implant provisionalization lacked in the literature. Hence, our study was conducted with an aim to assess the changes in the soft tissue, hard tissue, and esthetic outcomes following immediate implants with provisionalization with or without bone grafting.

Materials and methods: Twenty patients with a mean age between 18 and 55 years referred to the department of periodontology, for immediate implant placement in maxillary anterior region were included in the study. Patients were enrolled into two groups. Group I (test group) included patients with immediate implant placement with provisionalization with bone grafting. Group II (control group) included patients with immediate implant placement with provisionalization without bone grafting. Cement-retained provisional restoration was fitted over temporary abutment for 6 months of healing period. After 6 months of implant placement, definite crown was delivered.

Results: The results of our study showed the least resorption of buccal cortical plate and good amount of bone gain in both the groups in terms of horizontal alveolar dimensional changes. The mean amount of horizontal alveolar gain in group I was $1.12 \mathrm{~mm}$ at $2 \mathrm{~mm}, 1.08 \mathrm{~mm}$ at $4 \mathrm{~mm}$, and $0.85 \mathrm{~mm}$ at $6 \mathrm{~mm}$; in group II, it was $0.97 \mathrm{~mm}$ at $2 \mathrm{~mm}, 1.4 \mathrm{~mm}$ at $4 \mathrm{~mm}$, and $0.93 \mathrm{~mm}$ at $6 \mathrm{~mm}$.

Conclusion: This study showed a significantly better outcome in both the groups in terms of all the parameters when compared from baseline but the mean differences between the two groups were not very significant. The study concluded that immediate implant with provisionalization with or without bone grafting has maintained stability of soft tissues as well as hard tissues and has also given better esthetic outcomes.

Clinical significance: The findings of this study proved that immediate implant placement with provisionalization with bone grafting is a predictable treatment modality that maintains the three-dimensional stability of alveolar bone and integrity of soft tissue and gives acceptable esthetics. Hence, this technique promises to fulfill both functional and esthetic concerns of the patient.

Keywords: Esthetic zone, Immediate implant, Provisionalization.

The Journal of Contemporary Dental Practice (2021): 10.5005/jp-journals-10024-3158
\end{abstract}

\section{INTRODUCTION}

The clinical replacement of lost natural teeth by osseointegrated implants is one of the most significant advances in restorative dentistry. ${ }^{1}$ The relevance of immediate implant placement in maxillary anterior region is increasing due to the advantage offered by immediate implants, such as reduction in resorption of alveolar process that takes place following tooth extraction. ${ }^{2}$ Soft tissue esthetics around immediate implants is a prime criterion to evaluate the success along with osseointegration. ${ }^{3}$ Clinical studies have also reported the existence of dehiscence defects that lacks the potential for regeneration and possesses the risk for long-term soft tissue complications with immediate implants in the anterior zone.

The concept of provisionalization is becoming popular with immediate implants due to tissue conditioning effect offered. Furthermore, provisional restoration acts as a prosthetic socket sealing device to protect, contain, and maintain blood clots and bone graft material during the healing phase of treatment. Bone grafts help in achieving bone regeneration in defective sites adjacent to immediate implants using variety of bone augmentation techniques. ${ }^{4}$

However, there is not much reliable conclusive evidence in supporting or refuting the need for bone augmentation procedures parallel to provisionalization with immediate implants, due to the fact that bone grafts may pose the concerns of presence of residual particles under provisional restoration, which interferes with normal healing process and bone to implant contact. Hence, our study was
${ }^{1-6}$ Department of Periodontics, Albadar Rural Dental College, Kalaburagi, Karnataka, India

Corresponding Author: Neha Bhutani, Department of Periodontics, Albadar Rural Dental College, Kalaburagi, Karnataka, India, Phone: +918178505741, e-mail: nehabhutaniperio@gmail.com

How to cite this article: Bhutani N, Fatima G, Rampure N, et al. Esthetic Evaluation of Maxillary Anterior Immediate Implant with Provisionalization with or without Bone Grafting. J Contemp Dent Pract 2021;22(10):1105-1112.

Source of support: Nil

Conflict of interest: None

done with the aim to assess the changes in the soft tissue, hard tissue, and esthetic outcomes following immediate implants with provisionalization with or without bone grafting.

\section{Methodology}

The study included 20 patients aged between 18 and 55 years reported to the department of periodontics, Al-Badar Rural Dental College, Kalaburagi, for placement of single endosteal implant in the maxillary anterior region. The sample size of the study was estimated using the formula, $n=\left(Z^{2}(p)(1-p) / C^{2}\right.$. where, $Z$ value $=1.96$ set at $95 \%$ confidence level $p=$ probability picking a sample $=0.5, C=$ confidence interval $=0.3099$. Ethical clearance was received from the Institutional Ethics committee (IEC), Al-Badar 
Dental College and Hospital with reference number (IEC/2018-1907). The inclusion criteria were as follows: 1 . nonsmokers, 2 . patients in need for extraction and immediate replacement of maxillary anterior teeth in esthetic zone (from maxillary right first premolar to maxillary left first premolar), 3. no periodontal disease or gingival recession present, 4 . no restoration on contralateral natural tooth, and 5. no endodontic lesion with facial plate perforation or dehiscence. Exclusion criteria included were as follows: 1. history of allergic reaction to local anesthetic agents, 2. medically compromised patients, 3. pregnant or lactating women, 4. compromised soft tissue conditions, 5. poor patient compliance, 6. allergy to nonsteroidal anti-inflammatory drugs, and 7. history of any localized or systemic infection or any other periodontal surgical procedure within 4 weeks of duration. The study was conducted as a randomized controlled clinical trial; patients were enrolled into two groups by the coin toss method of randomization. Patients assigned to group I (test group) received immediate implant with provisionalization with bone grafting. Patients assigned to group II (control group) received immediate implant with provisionalization without bone grafting. A preliminary clinical evaluation, diagnostic wax up, and cone-beam computer tomography (CBCT) scan were carried out for appropriate treatment planning and to know bone defect morphology to calculate the amount of bone graft needed during the surgical procedure.

\section{Surgical Procedure}

Teeth indicated for extraction were removed in an atraumatic manner under local anesthesia taking extra care to preserve the buccal plate. A socket was debrided thoroughly and disinfected with tetracycline hydrochloride. The dimensions of socket were evaluated intraoperatively and related with the findings of CBCT to finalize the dimension of implant used. Osteotomy was performed and internally hexed Adin (Touareg ${ }^{\text {TM }} \mathrm{S}$ ) implant was placed using 30-40 N torque. Apicocoronal position of the implant platform was positioned $2 \mathrm{~mm}$ below the gingival zenith of adjacent teeth. According to the requirement of test group (Figs $1 A$ to $G$ and $2 A$ to $D$ ) or control group (Figs $3 \mathrm{~A}$ to $\mathrm{F}$ and $4 \mathrm{~A}$ to $\mathrm{C}$ ), the labial gap was either contained blood clot or was filled with bone graft (osteon II). Cement- or screw-retained provisional restoration was then fabricated using autopolymerizing acrylic resin in infraocclusion. For both the test group and control group, patients were placed on postsurgical antibiotics. For both the groups, a minimum of 6 months of healing period was given before the removal of provisional restoration for implant level impression for fabrication of definitive restoration. After removal of provisional restoration, ceramo-metal definitive crowns were delivered. All the surgical procedures were performed by single clinician while follow-up was done by other clinician, a single blind clinical trial.

\section{Outcome Variables}

Patients were evaluated for soft tissue parameters, esthetic outcomes, and hard tissue parameters.

\section{Soft Tissue Parameters}

Clinical conditions of soft tissue around the restoration were evaluated three times, i.e., baseline (after immediate provisionalization, 3 months after provisionalization, and 6 months after provisionalization) by means of the following parameters.

- Plaque scores: A dichotomous score was given (0-no visible plaque at soft tissue margin, 1 -visible plaque at soft tissue margin) and evaluated at four sites per implant (mesial, midfacial, distal, palatal), and mean score of that patient was calculated by dividing total score by number of surfaces examined. ${ }^{5}$

- Bleeding on probing: A dichotomous score was given (0-no bleeding, 1-bleeding) at four sites per implant (mesial, distal,
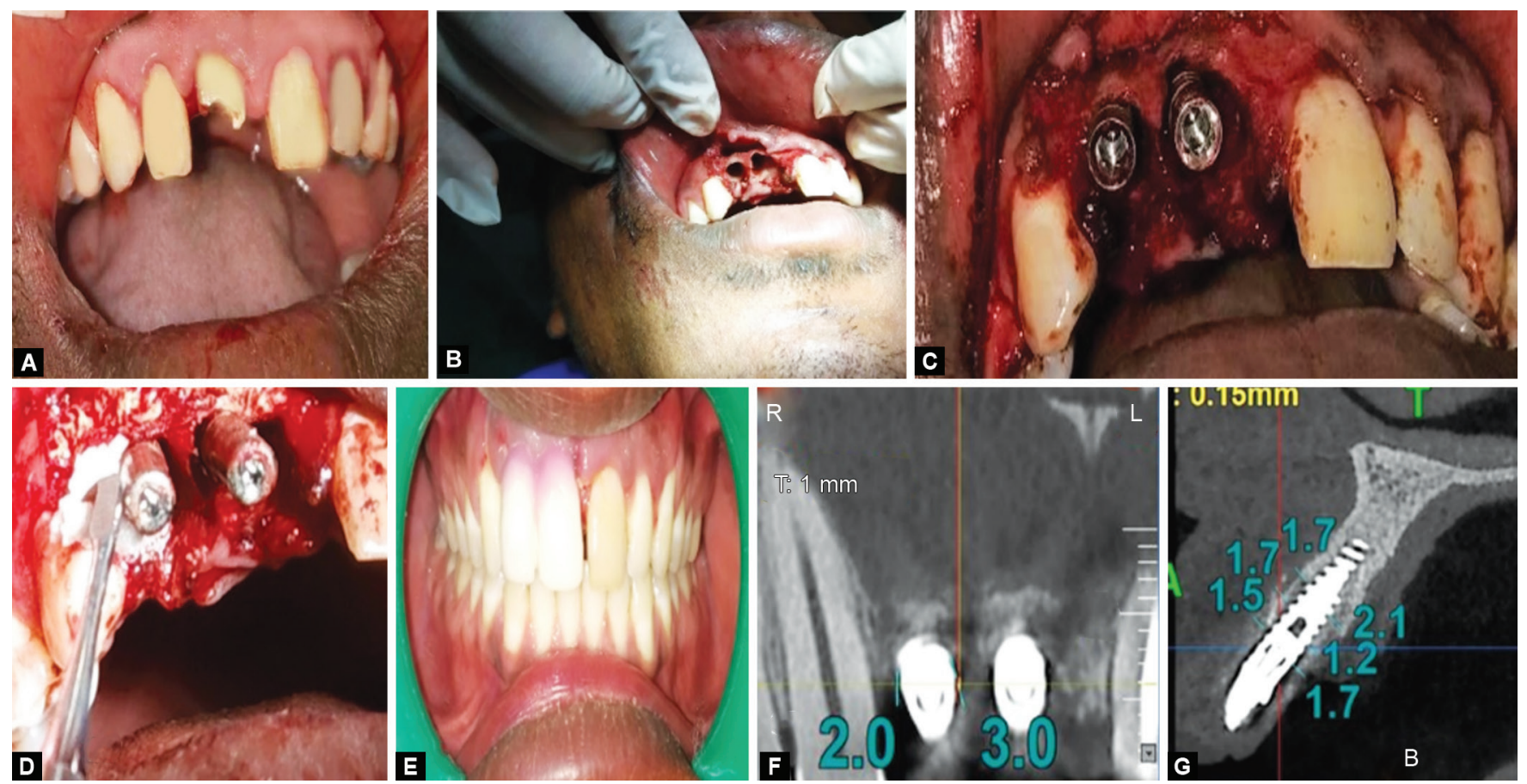

Figs 1 A to G: (A) Preoperative clinical view of patient; (B) Socket debrided; (C) Implant positioned; (D) Socket grafted and temporary abutment positioned; (E) Provisionalization done; (F) CBCT image showing mesial and distal vertical dimensions following 7 days of implant placement; (G) CBCT image showing buccal and palatal dimension following 7 days of implant provisionalization 

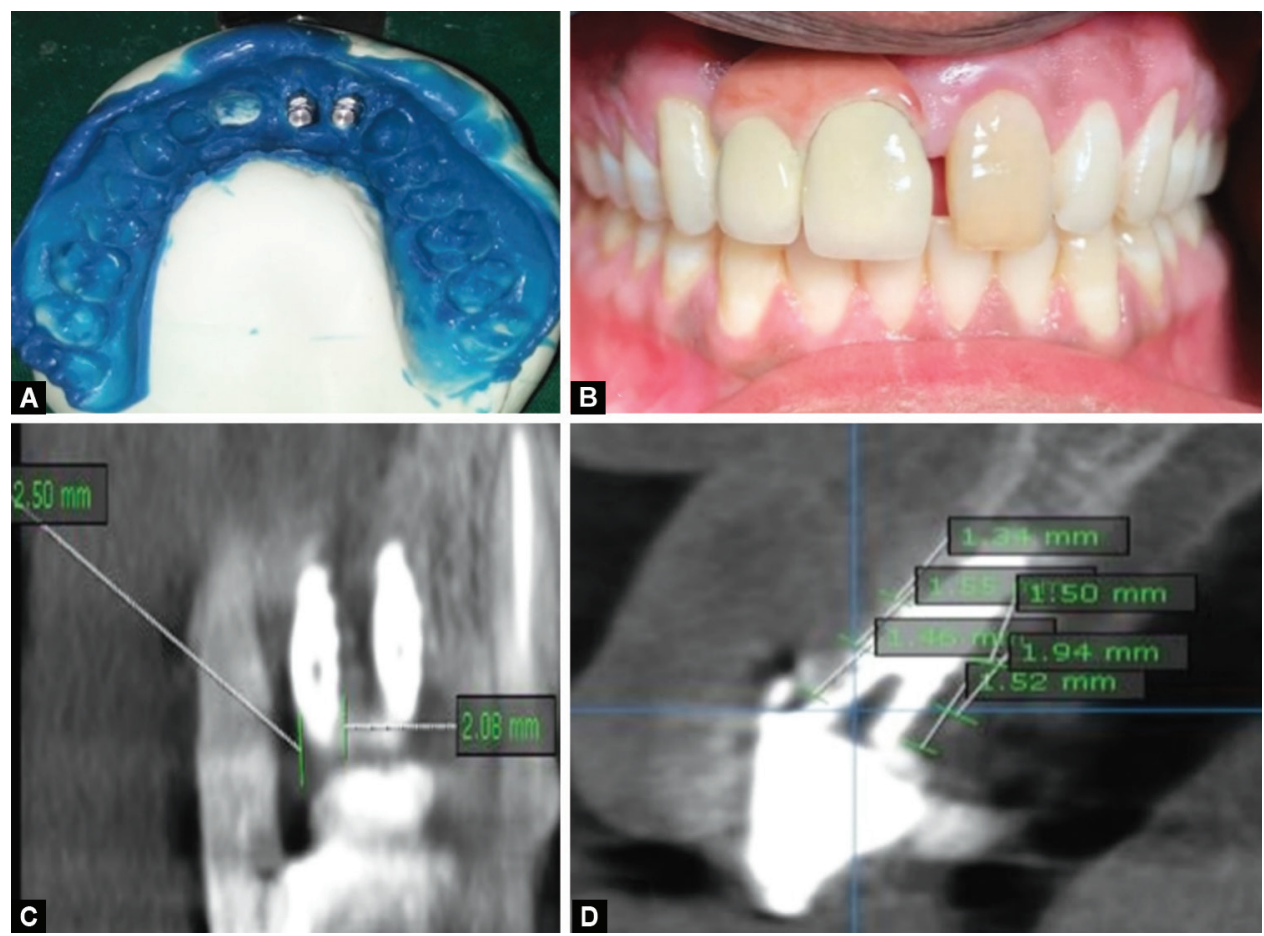

Figs 2A to D: (A) Final Impression recorded; (B) Definitive crown delivered; (C) CBCT image showing mesial and distal vertical crestal changes following 6 months of implant provisionalization; (D) CBCT image showing horizontal buccal and palatal changes following 6 months of implant provisionalization
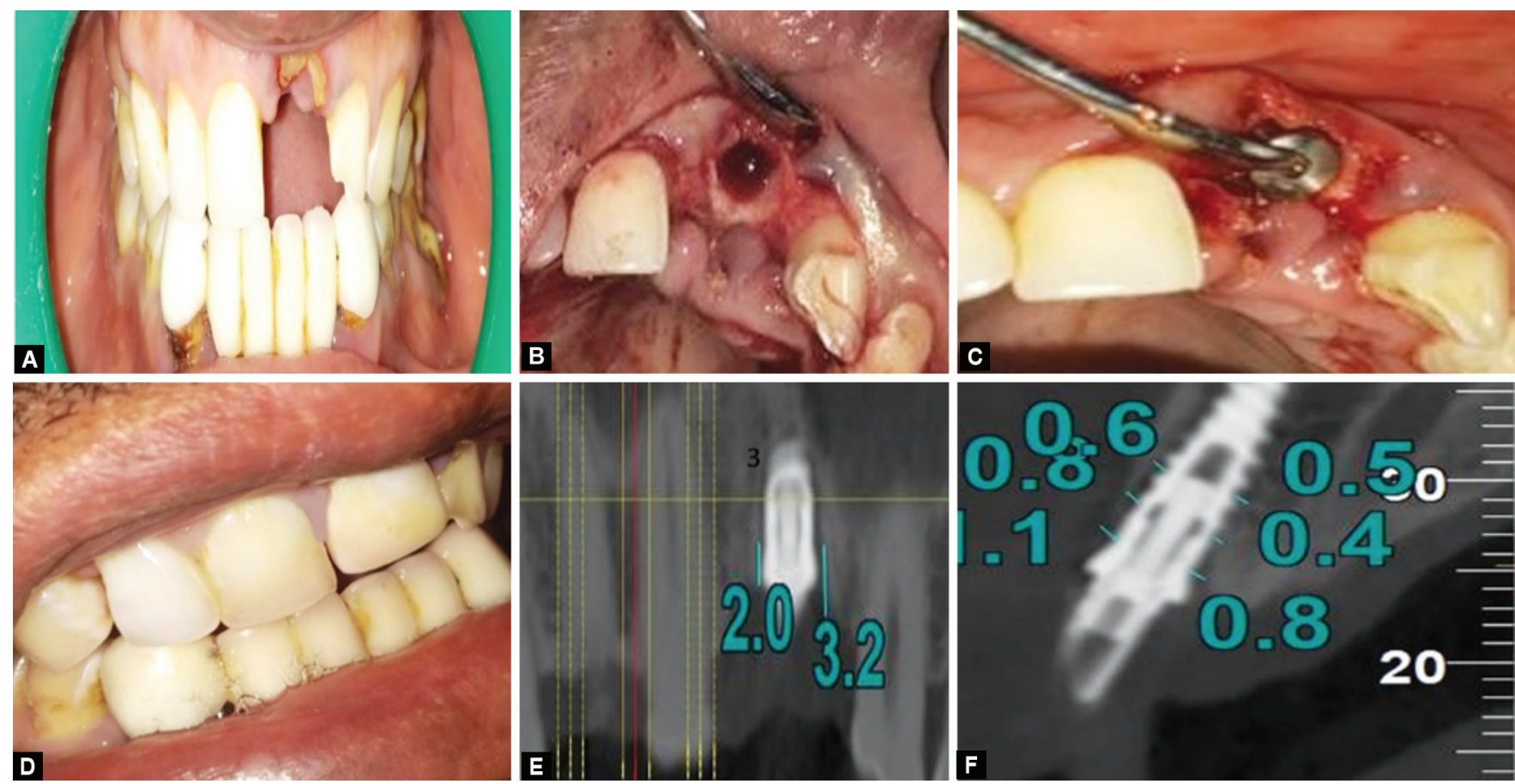

Figs 3A to F: (A) Preoperative clinical view of patient; (B) Extraction done; (C) Implant positioned; (D) Provisionalization done; (E) CBCT image showing mesial and distal vertical dimension following implant provisionalization; (F) CBCT image showing buccal and palatal dimensions following implant provisionalization

midfacial, palatal), and mean bleeding score was calculated by dividing total score by number of surfaces examined. ${ }^{5}$

- Marginal tissue recession at midbuccal aspect:Tissue recession was evaluated using a digital caliper. For calculating the recession position of marginal tissue relative to the known length of the provisional crown was evaluated in $\mathrm{mm}$ at two intervals: (1) baseline to 3 months and (2) 3 months to 6 months. Baseline measurement for the position of gingival margin is obtained by 

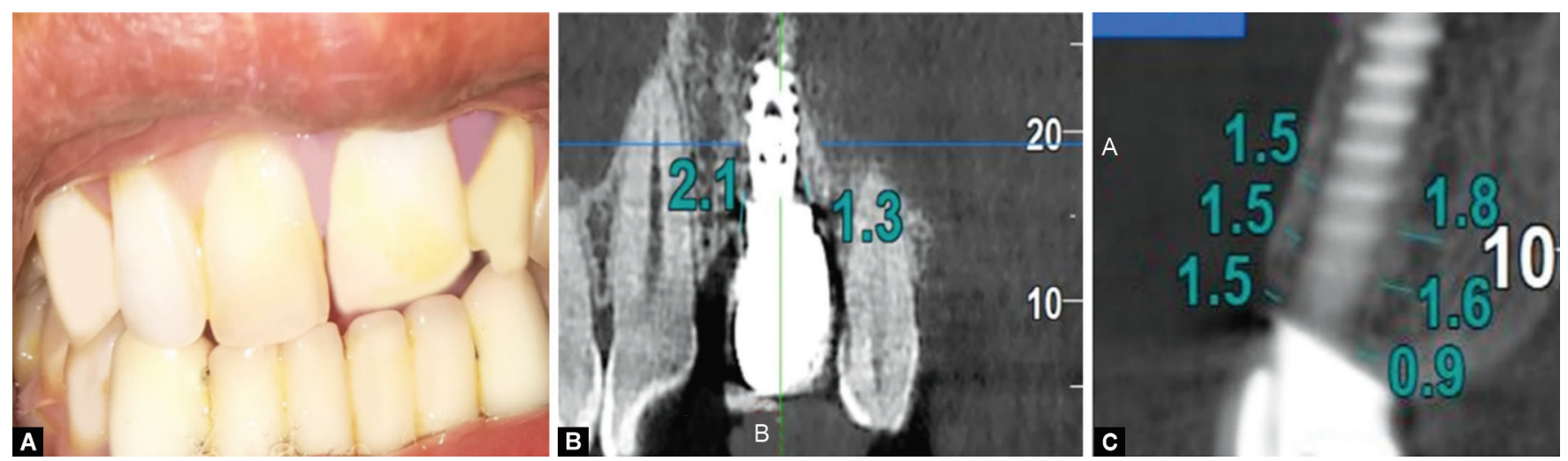

Figs 4A to C: (A) Definitive crown delivered; (B) CBCT image showing mesial and distal vertical crestal changes following 6 months of implant provisionalization; (C) CBCT image showing horizontal buccal and palatal changes following 6 months of implant provisionalization

subtracting the height of clinically visible crown from the known height of provisional crown. Then the recession of peri-implant mucosa was calculated by evaluating the difference in position of marginal tissue from baseline to 3 months and from 3-6 months.

- Peri-implant sulcular depth: It was measured at the nearest of $0.5 \mathrm{~mm}$ at four sites per implant (mesial, distal, midfacial, palatal) using plastic probe.

\section{Esthetic Outcomes}

All esthetic evaluations related to soft tissues around implants were performed at baseline, 3 , and 6 months. Implant esthetic index given by Testori et al. consisting of five variables was used for esthetic evaluation. ${ }^{6}$

Scoring criteria for five variables of implant esthetic index were as follows:

- Presence and stability of the mesiodistal papilla: $0=$ no papilla, $1=$ does not fill the entire space but is esthetically acceptable in harmony with adjacent teeth, and $2=$ total fill. To follow up the dimensional stability of the papilla, the vertical distance from the apex of the mesiodistal papilla to the imaginary line connecting the cementoenamel junction (CEJ) of the two adjacent teeth and the height of the mesiodistal papilla should be periodically measured with reference to this line.

- Ridge stability buccopalatally: 0 = width maintained and $1=$ width with ridge loss. Ridge stability is measured in millimeters of buccal resorption with respect to adjacent natural teeth from the baseline line (i.e., temporary crown delivery) to following recall 6 months. Study models fabricated at final crown delivery may facilitate evaluation of buccal resorption over time.

- Texture of the peri-implant soft tissue: $0=$ complete loss of texture, $1=$ does not look like healthy tissue, but some texture still maintained, and $2=$ looks like healthy gingival tissue around the natural teeth.

- Color of the peri-implant soft tissue: $0=$ completely different color from healthy tissue, $1=$ does not look like healthy tissue but still esthetically acceptable, and $2=$ looks like healthy gingival tissue around the natural teeth.

- Gingival contour: 0 = evident asymmetry from the accepted parameters of scalloping, 1 = signs of asymmetry but esthetically acceptable, and $2=$ harmonious gingival contour.

A total of 9-point score can be obtained, which reflects the perfect outcome. The acceptable outcome can be seen in cases with a score of 4-8 and 0-3 points reflects compromised esthetic outcome.

\section{Hard Tissue Parameters}

All the patients underwent $\mathrm{CBCT}$ examination at baseline, i.e., after implant provisionalization (T1) and 6 months after provisionalization (T2). The difference in bone changes between $\mathrm{T} 1$ and $\mathrm{T} 2$ was calculated using the following landmarks.

S-Surface of implant (tip of thread)

B-Most coronal bone to implant contact on buccal side.

C-Top of bone crest (mesial, distal, buccal, palatal)

A-Apex of implant

IC-Inner border of bone crest.

OC-Outer border of bone crest.

I-First thread of Implant.

The following measurements were obtained: mesial and distal vertical crestal changes - for vertical crestal changes at mesial and distal sites, changes in the distance between I and C are measured and compared from baseline to 6 months and for horizontal buccal and palatal changes, measurements between points IC and $S$ at the level of 2,4 , and $6 \mathrm{~mm}$ were observed and compared.

\section{Statistical Analysis}

The intergroup comparison was done by using the unpaired Student ' $t$ ' test, and the intragroup comparison was done by using the paired Student ' $t$ ' test. The statistical data were analyzed by using IBM SPSS 20.0 version software.

\section{Results}

Out of a total of 20 participants, 8 were female and 12 were males. The mean age of participants was $36.3 \pm 5.81$ years in group I and $35.4 \pm 6.65$ years in group II.

\section{Soft Tissue Parameters}

\section{Plaque Index}

Plaque index around implant restoration was reduced over a period of 6 months for both the groups indicating a sound healthy mucosa and tissue integration around implant provisional. The difference in the mean plaque score between the groups at all time periods was not significant. The mean plaque index score for the test group was $0.70 \pm 0.16$ and for the control group was $0.82 \pm 0.11$ at the end of 6 months. 


\section{Bleeding on Probing}

There was no statistically significant difference of mean bleeding on probing index score from baseline to 3 months in groups I and II $(p>0.05)$. Whereas, there was highly significant difference of mean bleeding on probing index observed from baseline to 6 months in groups I and II. At the end of 6 months follow-up, the mean bleeding on probing index score was significantly reduced as compared to baseline. The mean bleeding on probing index at 6 months for group I was 0.70 and for group II, it was 0.80 . Low values of bleeding on probing around implant appear to confirm that patients enrolled for implant therapy in general were cooperative with good compliance and maintained good oral hygiene practices.

\section{Gingival Recession}

There were no statistically significant changes observed in the mean gingival level from baseline to 3 months and 3-6 months in both the groups. However, group I showed greater reduction in mean gingival recession when observed from baseline $(0.63 \pm 0.22)$ to 6 months $(0.46 \pm 0.18)$.

\section{Peri-implant Sulcular Depth}

Mean probing depth at different sites in group I and group II is depicted in Table 1. The difference in mean pocket depth at each site between 3 and 6 months is nonsignificant in both the groups except for the distal aspect in group I where it showed greater reduction as compared to other sites. Comparison between the two groups at different sites and time period of evaluations showed no statistically significant difference of mean mesial, midbuccal, and distal pocket depth; however, at palatal aspect, the pocket depth in group I showed significant difference when compared to group II at 6 months follow-up, signifying greater reduction in pocket depth in group I at palatal aspect compared to group II at 6 months follow-up.

\section{Implant Esthetic Score}

No statistically significant difference of mean esthetic score between time interval of baseline and 3 months and baseline and 6 months for the variables A, B, C, D, and $E$ was observed in any of the groups ( $p>0.05$ ) (Tables 2 and 3 ). These values suggested favorable overall peri-implant soft tissue conditions and ridge stability for both the groups. The study observed that total mean esthetic score of group I was 7.37, which is greater as compared to group II with mean score of 6.77 but it was not statistically significant. There were no cases with total score of 3 or less in both the groups at baseline and follow-up periods, which could be regarded as esthetic failure.

\section{Hard Tissue Parameters Vertical Crestal Changes}

The mean vertical distance between mesial and distal crest to the first thread of implant was analyzed at baseline and 6 months; the mean distance was found to be increased for both the groups signifying bone gain in vertical direction at interproximal aspect. There was statistically significant difference of mean dimensional mesial crestal changes observed from baseline to 6 months in both

Table 1: Comparison of peri-implant sulcular depth score with time intervals between group I and group II

\begin{tabular}{|c|c|c|c|c|}
\hline \multirow[b]{2}{*}{ Variables } & \multirow[b]{2}{*}{ Time interval } & \multirow{2}{*}{$\begin{array}{c}\text { Group I } \\
\text { Mean } \pm S D\end{array}$} & \multirow{2}{*}{$\begin{array}{c}\text { Group II } \\
\text { Mean } \pm S D\end{array}$} & \multirow[b]{2}{*}{ Unpaired t test and $p$ value } \\
\hline & & & & \\
\hline \multirow[t]{2}{*}{ Mesial } & 3 months & $1.00 \pm 0.47$ & $1.00 \pm 0.47$ & $t=0.000, p=1.000, \mathrm{NS}$ \\
\hline & 6 months & $0.80 \pm 0.42$ & $0.80 \pm 0.42$ & $t=0.000, p=1.000, \mathrm{NS}$ \\
\hline \multirow[t]{2}{*}{ Midbuccal } & 3 months & $0.60 \pm 0.52$ & $0.60 \pm 0.52$ & $t=0.000, p=1.000, \mathrm{NS}$ \\
\hline & 6 months & $0.50 \pm 0.53$ & $0.50 \pm 0.53$ & $t=0.000, p=1.000, \mathrm{NS}$ \\
\hline \multirow[t]{2}{*}{ Distal } & 3 months & $0.70 \pm 0.48$ & $0.70 \pm 0.48$ & $t=0.000, p=1.000, \mathrm{NS}$ \\
\hline & 6 months & $0.40 \pm 0.52$ & $0.70 \pm 0.48$ & $t=1.342, p=0.196, \mathrm{NS}$ \\
\hline \multirow[t]{2}{*}{ Palatal } & 3 months & $0.60 \pm 0.52$ & $0.80 \pm 0.42$ & $t=0.949, p=0.355, \mathrm{NS}$ \\
\hline & 6 months & $0.40 \pm 0.52$ & $0.80 \pm 0.42$ & $t=2.192, p=0.049, \mathrm{~S}$ \\
\hline
\end{tabular}

Table 2: Comparison of esthetic scores of five variables at different time intervals in group I

\begin{tabular}{llccc}
\hline \multirow{2}{*}{ Categories } & \multicolumn{2}{c}{ Esthetic score group I } & \\
\cline { 3 - 4 } A & Baseline and 3 months & $1.70 \pm 0.48$ & $1.80 \pm 0.42$ & $t=1.000, p=0.343, \mathrm{NS}$ \\
& Baseline and 6 months & $1.70 \pm 0.48$ & $1.90 \pm 0.32$ & $t=1.50, p=0.168, \mathrm{NS}$ \\
B & Baseline and 3 months & $0.50 \pm 0.50$ & $0.50 \pm 0.50$ & $t=0.000, p=1.00, \mathrm{NS}$ \\
& Baseline and 6 months & $0.50 \pm 0.50$ & $1.13 \pm 0.83$ & $t=1.964, p=0.081, \mathrm{NS}$ \\
C & Baseline and 3 months & $1.40 \pm 0.52$ & $1.600 \pm 0.52$ & $t=1.500, p=0.168, \mathrm{NS}$ \\
& Baseline and 6 months & $1.40 \pm 0.52$ & $1.60 \pm 0.52$ & $t=1.500, p=0.168, \mathrm{NS}$ \\
D & Baseline and 3 months & $1.60 \pm 0.52$ & $1.70 \pm 0.48$ & $t=1.000, p=0.343, \mathrm{NS}$ \\
& Baseline and 6 months & $1.60 \pm 0.52$ & $1.70 \pm 0.48$ & $t=1.000, p=0.343, \mathrm{NS}$ \\
E & Baseline and 3 months & $1.60 \pm 0.49$ & $1.70 \pm 0.48$ & $t=1.000, p=0.343, \mathrm{NS}$ \\
& Baseline and 6 months & $1.60 \pm 0.49$ & $1.60 \pm 0.49$ & $t=0.000, p=1.000, \mathrm{NS}$ \\
\hline
\end{tabular}


Table 3: Comparison of esthetic scores of five variables at different time intervals in group II

\begin{tabular}{lllll}
\hline & & \multicolumn{2}{c}{ Esthetic score group II } & \\
\cline { 3 - 4 } Categories & Comparison & Mean \pm SD & Mean \pm SD & Paired t test and $p$ value \\
\hline A & Baseline and 3 months & $1.70 \pm 0.48$ & $1.60 \pm 0.52$ & $t=1.000, p=0.343, \mathrm{NS}$ \\
& Baseline and 6 months & $1.70 \pm 0.48$ & $1.90 \pm 0.32$ & $t=0.000, p=1.000, \mathrm{NS}$ \\
B & Baseline and 3 months & $0.50 \pm 0.53$ & $0.40 \pm 0.52$ & $t=1.000, p=0.343, \mathrm{NS}$ \\
& Baseline and 6 months & $0.50 \pm 0.53$ & $0.60 \pm 0.52$ & $t=0.557, p=0.591, \mathrm{NS}$ \\
C & Baseline and 3 months & $1.40 \pm 0.52$ & $1.30 \pm 0.48$ & $t=0.557, p=0.591, \mathrm{NS}$ \\
& Baseline and 6 months & $1.40 \pm 0.52$ & $1.30 \pm 0.48$ & $t=0.557, p=0.591, \mathrm{NS}$ \\
D & Baseline and 3 months & $1.50 \pm 0.53$ & $1.40 \pm 0.70$ & $t=1.000, p=0.343, \mathrm{NS}$ \\
& Baseline and 6 months & $1.50 \pm 0.53$ & $1.50 \pm 0.70$ & $t=0.000, p=1.000, \mathrm{NS}$ \\
$\mathrm{E}$ & Baseline and 3 months & $1.50 \pm 0.53$ & $1.40 \pm 0.52$ & $t=1.000, p=0.343, \mathrm{NS}$ \\
& Baseline and 6 months & $1.50 \pm 0.53$ & $1.40 \pm 0.52$ & $t=1.000, p=0.343, \mathrm{NS}$ \\
\hline
\end{tabular}

Table 4: Comparison of vertical crestal changes with time interval between group I and II

\begin{tabular}{|c|c|c|c|c|}
\hline \multirow[b]{2}{*}{ Variables } & \multirow[b]{2}{*}{ Time interval } & \multirow{2}{*}{$\begin{array}{c}\text { Group I } \\
\text { Mean } \pm S D\end{array}$} & \multirow{2}{*}{$\frac{\text { Group II }}{\text { Mean } \pm S D}$} & \multirow[b]{2}{*}{ Unpaired t test and $p$ value } \\
\hline & & & & \\
\hline \multirow[t]{2}{*}{ Mesial } & Baseline & $3.06 \pm 0.12$ & $3.16 \pm 0.62$ & $t=0.492, p=0.627, \mathrm{NS}$ \\
\hline & 6 months & $3.14 \pm 0.15$ & $3.10 \pm 0.53$ & $t=0.228, p=0.822, \mathrm{NS}$ \\
\hline \multirow[t]{2}{*}{ Distal } & Baseline & $3.02 \pm 0.14$ & $3.05 \pm 0.39$ & $t=0.225, p=0.850, \mathrm{NS}$ \\
\hline & 6 months & $3.07 \pm 0.11$ & $3.10 \pm 0.37$ & $t=0.246, p=0.811, \mathrm{NS}$ \\
\hline
\end{tabular}

the groups. In comparison between the two groups, no statistically significant difference was observed between two groups at mesial and distal aspects at all time intervals (Table 4).

\section{Horizontal Buccal Changes in Group I}

Table 5 depicts the mean horizontal dimensions at buccal aspect for different time intervals at 2, 4, and $6 \mathrm{~mm}$. After 6 months of healing, the mean difference of radiographic horizontal alveolar change was 1.12 at $2 \mathrm{~mm}, 1.08$ at $4 \mathrm{~mm}$, and 0.85 at $6 \mathrm{~mm}$. This value with positive symbol indicates very highly significant bone gain at buccal aspect at each measurement.

\section{Horizontal Buccal Changes Group II}

Table 6 depicts the mean difference of values at different time intervals at 2, 4, and $6 \mathrm{~mm}$ of buccal aspect. After 6 months of healing, the mean difference of radiographic horizontal alveolar change was 0.97 at $2 \mathrm{~mm}, 1.0$ at $4 \mathrm{~mm}$, and 0.93 at $6 \mathrm{~mm}$ in group II indicating bone gain. There was no statistically significant difference of mean horizontal changes at buccal aspect from baseline and 6 months between groups I and II ( $p>0.05)$.

There was very minimum horizontal resorption of alveolar plate in each group at buccal aspect observed at $3 \mathrm{~mm}$, and the obtained mean was $0.13 \mathrm{~mm}$ for group 1 and $0.16 \mathrm{~mm}$ in group II. The value shows nonsignificant difference of $0.03 \mathrm{~mm}$ between the two groups.

\section{Horizontal Palatal Dimensional Changes}

The mean horizontal palatal dimensional changes from baseline to 6 months in group I and group II was assessed at 2, 4, and $6 \mathrm{~mm}$. The defects appeared to be reduced even at palatal aspect with mean reduction of $0.11,0.10$, and $0.09 \mathrm{~mm}$ at 2,4 , and $6 \mathrm{~mm}$, respectively, in group 1 and $0.11,0.03$, and $0.07 \mathrm{~mm}$ at 2, 4, and $6 \mathrm{~mm}$, respectively, in group II. In comparison between two groups, the difference in mean palatal horizontal changes from baseline to 6 months at all millimeters was not significant.

\section{Discussion}

The concept of osseointegration described by Branemark (1977) led to predictable success of oral implants to replace missing teeth. The rationale for choosing immediate implant in our study was with the fact that immediate implant placement and loading in patients with terminal dentition has the potential to immediately transform the patient's quality of life.

Considering the fact of defective and deficient soft tissue closure and buccal bone voids with immediate implant leading to peri-implant mucosal recession; several treatment approaches have been advised with immediate implants. In our study, we evaluated the adjunctive role of provisional restoration and use of bone grafts under provisional restoration for enhancing results with immediate implant in esthetic zone.

Araujo et al. based on collected preliminary data concluded that immediate provisionalization helps in maintenance of both height and width of residual ridge and also supports peri-implant tissue with the preservation of interdental papilla. ${ }^{8}$ In our study, all the minimum criteria given by Curtis and Thomas $^{9}$ for successful provisionalization were followed. As a result, no uneventful situation due to or after the placement of provisional crowns was recorded and all the implants maintained osseointegration throughout the study.

In our study, provisional crown was provided with a cement escape vent at distal aspect of incisal surface at crown that ensured the marginal fit. ${ }^{10}$ The presence of abutment access hole for reinsertion of crown whenever needed was also ensured for provisional crowns. Occlusal and eccentric contacts were also eliminated for nonfunctional loading to enhance healing after insertion of provisional restoration.

Several reports have shown that bone augmentation can be achieved in this defective bony wall occurring due to preexisting pathology and tooth extraction adjacent to immediate implant using a variety of techniques or bone grafts. ${ }^{11}$ However, the 
Esthetic Evaluation of Maxillary Anterior Implant with Provisionalization and Grafting

Table 5: Comparison of horizontal buccal dimensional changes with time interval in group I

\begin{tabular}{lllllll}
\hline & & \multicolumn{2}{c}{ Group I } & & Difference & \\
\cline { 3 - 4 } Variables & Time interval & Mean $\pm S D$ & Mean $\pm S D$ & & Mean & Paired t test and $p$ value \\
\hline $2 \mathrm{~mm}$ & Baseline to 6 months (T1-T2) & $1.52 \pm 0.27$ & $0.41 \pm 0.07$ & & 1.12 & $t=13.278, p=0.000, \mathrm{VHS}$ \\
$4 \mathrm{~mm}$ & Baseline to 6 months (T1-T2) & $1.50 \pm 0.29$ & $0.43 \pm 0.16$ & & 1.08 & $t=10.815, p=0.000, \mathrm{VHS}$ \\
$6 \mathrm{~mm}$ & Baseline to 6 months (T1-T2) & $1.39 \pm 0.12$ & $0.46 \pm 0.07$ & 0.85 & $t=18.768, p=0.000, \mathrm{VHS}$ \\
\hline
\end{tabular}

Table 6: Comparison of horizontal buccal dimensional changes with time interval in group II

\begin{tabular}{llccccc} 
& & \multicolumn{2}{c}{ Group II } & & Difference & \\
\cline { 3 - 4 } Variables & Time interval & Mean $\pm S D$ & Mean $\pm S D$ & & Mean & Paired t test and $p$ value \\
\hline $2 \mathrm{~mm}$ & Baseline to 6 months (T1-T2) & $1.50 \pm 0.26$ & $0.52 \pm 0.21$ & & 0.97 & $t=19.138, p=0.000, \mathrm{VHS}$ \\
$4 \mathrm{~mm}$ & Baseline to 6 months (T1-T2) & $1.53 \pm 0.28$ & $0.52 \pm 0.22$ & & 1.0 & $t=14.982, p=0.000, \mathrm{VHS}$ \\
$6 \mathrm{~mm}$ & Baseline to 6 months (T1-T2) & $1.44 \pm 0.14$ & $0.51 \pm 0.12$ & 0.93 & $t=21.988, p=0.000, \mathrm{VHS}$ \\
\hline
\end{tabular}

literature lacks conclusive evidence supporting use of bone grafts parallel to immediate implants. According to many studies, bone grafts with immediate implants and under provisional restorations possess the concern of presence of residual particle that interferes with normal healing and bone to implant contact. There are also critical reports questioning the quality of regenerated bone around immediate implant determining their long-term predictability. It is also proved that micro-movement of grafted material beyond a certain limit between bone and implant prevents bone formation resulting in the development of fibrous tissue. ${ }^{12}$

In our study, we have evaluated the use of alloplastic grafting material under provisional restoration for enhancing results with immediate implant. The alloplastic material used in our study is osteon II, which is a newer osteoconductive biphasic calcium phosphate synthetic graft material composed of HA scaffold and $\beta$ tricalcium phosphate in a 30:70 ratio, respectively. Due to the higher concentration of $\beta$ tricalcium phosphate, the graft material is highly resorbable with excellent repair. It is highly porous enhancing better blood supply and greater surface for new cell attachment, which allows quicker healing time and more efficient bone formation. ${ }^{13,14}$

In our study, immediate provisionalization after implant placement in the esthetic zone achieved good results, in terms of all three parameters, such as soft tissue, hard tissue, and esthetics in both the groups. In comparison between the two groups, group I produced even better results than group II when seen collectively. The results of our study showed stability of peri-implant soft tissue, and the mean changes observed for gingival recession and peri-implant sulcular depth observed at different time periods were nonsignificant. The mean gingival recession in group I from baseline to 3 months was $0.53 \pm 0.13$ and from 3-6 months, it was $0.54 \pm 0$. Group II showed mean gingival recession of $0.53 \pm 0.13$ from baseline to 3 months and $0.57 \pm 0.18$ from 3-6 months. The results of our study in terms of gingival recession are in accordance with the previous studies conducted with the immediate implants that observed that mean recession of facial marginal mucosa occurs in the range between 0.5 and $0.9 \mathrm{~mm}^{15-18}$

The study done by Bauman et al. concluded that probing depth is more accurate means of detecting peri-implant destruction. He also suggested radiographic and probing measurements together to facilitate the accuracy and variability of comprehensive periimplant assessment. ${ }^{19}$ Mean probing depth observed for group I in our study at different sites by the end of 3 and 6 months was $1.00 \pm 0.42,0.82 \pm 0.42$ at mesial aspect; $0.62 \pm 0.52,0.50 \pm 0.53$ at midbuccal aspect; $0.70 \pm 0.48,0.42 \pm 0.52$ at distal aspect; and $0.60 \pm 0.52,0.40 \pm 0.52$ at palatal aspect.

The mean probing depth for group II was $1.00 \pm 0.47,0.80 \pm 0.42$ at mesial aspect; $0.60 \pm 0.52,0.50 \pm 0.53$ at midbuccal aspect; $0.70 \pm 0.48,0.40 \pm 0.52$ at distal aspect; and $0.60 \pm 0.52,0.40 \pm 0.52$ at palatal aspect. The difference in mean probing depths observed at different time intervals in both the groups was minimum, and greater reduction in the mean probing depth was observed at distal and palatal aspects in group I at 6 months follow-up. Hence, the results of our study in terms of probing depth showed more of stable tissue attachment till 6 months follow-up.

Contrary to our study, the study done by Buser and Weber showed a slight increase in probing depth over time with immediate implants and immediate nonfunctional loading. ${ }^{20}$ The increase in probing depth with time duration in their study could be attributed to the fact that they have intentionally nonsubmerged the implants in their study. In support to this study, Ricci suggested that pocket depth is not alone reliable enough to follow the soft tissue levels over time since it influences by changes in gingival anatomy. ${ }^{21}$

The mean total implant esthetics score obtained in our study for group I was $7.37 \pm 1.6$ and group II $6.77 \pm 1.73$. The mean score obtained in both the groups at different assessment periods signified that favorable esthetics were obtained in both the groups and slightly better in group I than group II.

Radiographically measured distance from bone to standard reference point reveals changes between the bones at different time periods. Each patient was provided with intraoral bite registration to facilitate the alignment of cone beam to provide standardization between the time periods. In terms of vertical bone changes at mesial aspect, the mean mesial bone gain was $0.08 \mathrm{~mm}$ in group I and group II. On distal aspect, the mean bone gain for the group I was 0.06 and group II was 0.05 . Mean gain observed in our study are comparable to a study done by Cooper and Lyndon, who evaluated immediate implants over a period of 5 years and reported mean gain of 2.06 and $2.38 \mathrm{~mm}$ on mesial and distal side, respectively, at the end of duration. ${ }^{22}$ The difference in the mean score between our study and their study could be attributed to the time duration of observation, which signifies apposition and maintenance of bone occur over a period of time.

After 6 months of evaluation, horizontal buccal gain amounted for group I at 2, 4, and $6 \mathrm{~mm}$ was $1.12,1.08$, and 0.85 , respectively, and for group II, it was $0.97,1$, and $0.9 \mathrm{~mm}$. The results obtained 
for group I showed more buccal bone gain than group II. But the comparison between groups showed nonsignificant results. The results of our study in terms of horizontal bone gain is in accordance with the study done by Rossi ${ }^{23}$ in which they evaluated hard tissue alteration at immediate implants with provisionalization and results obtained in terms of horizontal bone gain at buccal aspect were $1.2 \mathrm{~mm}$ at $3 \mathrm{~mm}$ and $1.3 \mathrm{~mm}$ at $5 \mathrm{~mm}$.

The buccal bone resorption was analyzed at $3 \mathrm{~mm}$ for both the groups, and only two patients in group I and three patients in group II showed alveolar horizontal buccal bone resorption; the mean buccal resorption for group I was $0.75 \mathrm{~mm}$ and group II was $0.8 \mathrm{~mm}$. The result obtained in our study showed a significant lesser value of alveolar resorption as compared to other studies. ${ }^{23}$ The decrease in the value could be attributed to the fact that provisionalization prevents buccal bone resorption. The results of our study also showed no vertical alveolar crestal bone resorption. However, there are few limitations in our study such as the study have not been done with the split-mouth design taking into consideration and also the only radiographic method of evaluation to assess the bone fill has been used in the study and no histologic investigations have been performed to reveal the true nature of the attachment. The future studies should incorporate a larger sample size with longer duration and different bone graft materials to assess bone fill.

\section{Conclusion}

The study concluded that anterior maxillary single-tooth implant replacement with immediate provisionalization with or without bone grafting is a successful and predictable treatment modality in terms of stability of soft tissue, maintenance of alveolar bone morphology as well as in esthetic point.

\section{References}

1. Pathak AK, Goel K. Periodontal parameters around implants and natural tooth. Natl J Maxillofac Surg 2016;7(1):52-55. DOI: 10.4103/0975-5950.196130.

2. Joshi V, Gupta S. Immediate implant placement in anterior esthetic region and assesment using cone beam computed tomographic scan technology. J Int Oral Health 2015;7(2):99-102. PMID: 26668494.

3. Singh A, Gupta A, Yadav A, et al. Immediate placement of implant in fresh extraction socket with early loading. Contemp Clin Dent 2012;3(6):219-222. DOI: 10.4103/0976-237X.101099.

4. Evans CDJ, Chen ST. Esthetic outcomes of immediate implant placements. Clin Oral Impl Res 2008;19(1):73-80. DOI: 10.1111/j.16000501.2007.01413.x.

5. Mombelli A, Lang NP. Clinical parameter for the evaluation of dental impants. Periodontol 2000 1994;4:81-86. DOI: 10.1111/j.16000757.1994.tb00008.x.

6. Testori T, Bianchi F, Fabbro MD, et al. Implant esthetic score for evaluating the outcome: immediate loading in the esthetic zone. Pract Proced Aesthet Dent 2005;12(2):123-130. PMID: 15918307.

7. Barndt $\mathrm{P}$, Zhang H, Liu F. Immediate loading: from biology to biomechanics. Report of the committee on research in fixed prosthodontics of the American Academy of fixed prosthodontics. JProstho Dent 2015;112(2):96-107.DOI: 10.1016/j.prosdent.2014.08.011.

8. Araujo MG, Sukekava F, Wennstr JL, et al. Ridge alterations following implant placement in fresh extraction sockets: an experimental study in the dog. J Clin Periodontol 2005;32(6):645-652. DOI: 10.1111/j.1600051X.2005.00726.x.

9. Curtis M,Thomas GW.Minimum criteriafor immediate provisionalization of single-tooth dental implants in extraction sites: a 1-year retrospective study of 100 consecutive cases. J Oral Maxillofac Surg 2011;69(2):491-497. DOI: 10.1016/j.joms.2010.10.024.

10. Allister MC. The rationale for the vented-crown technique and its application in today's dental practice. Oper Dent 2008;33(2):116-120. DOI: $10.2341 / 08-S A 1$.

11. Esposito M, Gabriella M, Pietro F. Timing of implant placement after tooth extraction: immediate, immediate-delayed or delayed implants? A Cochrane systematic review. Eur J Oral Implantol 2010;3(3):189-205. PMID: 20847990.

12. Chen $\mathrm{H}$, Lin $\mathrm{G}$. Alteration in bone quality after socket preservation with graft material a systematic review. Int J Oral Maxillofac Implants 2013;28(3):710-720. DOI: 10.11607/jomi.2913.

13. Kim YK, Yun PY, Lim SG, et al. Clinical evaluations of OSTEON as a new alloplastic material in sinus bone grafting and its effect on bone healing. J Biomed Mater Res Appl Biomater 2008;86(1):270-277. DOI: 10.1002/jbm.b.31015.

14. Erbe EM, Marx JG, Clineff TD, et al. Potential of an ultraporous betatricalcium phosphate synthetic cancellous bone void filler and bone marrow aspirate composite graft. Eur Spine J 2001;2(Suppl. 2):141-146. DOI: $10.1007 / \mathrm{s} 005860100287$.

15. Chen ST, Wilson TG. Immediate or early placement of implants following tooth extraction: review of biologic basis, clinical procedures, and outcomes. Int J Oral Maxillofac Implants 2004;19(19):12-25. PMID: 15635942.

16. Kois JC. Predictable esthetics: five diagnostic keys. Compend Contin Educ Dent 2001;22(3):199-206.

17. De Rouck T, Collys K, Cosyn J. Immediate single-tooth implants in the anterior maxilla: a 1-year case cohort study on hard and soft tissue response. J Clin Periodontol 2008;35(7):649-657. DOI: 10.1111/j.1600051X.2008.01235.x.

18. De Rouck T, Collys K, Wyn I, et al. Instant provisionalization of immediate single-tooth implants is essential to optimize esthetic treatment outcome. Clin Oral Impl Res 2009;7(4):566-570. DOI: 10.1111/j.1600-0501.2008.01674.x.

19. Bauman GR, Mills M, Rapley JW, et al. Clinical parameters of evaluation during implant maintenance. Int J Oral Maxillofac Impl 1992;7(4): 220-227. PMID: 139883919.

20. Buser D, Weber HP. Tissue integration of one-stage ITI implants: 3-year results of a longitudinal study with Hollow-Cylinder and HollowScrew implants. Int J Oral Maxillofac Implants 1991;6(4):L405-L412. PMID: 1820309.

21. Ricci G. Crestal bone resorption 5 years after implant loading: clinical and radiologic results with a 2-stage implant system. Int J Oral Maxillofac Implants 2004;19(4):597-602. PMID: 15346759.

22. Cooper M, Lyndon F. Immediate provisionalization of dental implants placed in healed alveolar ridges and extraction sockets: a 5-year prospective evaluation. Int J Oral Max Impl 2014;(3):709-717. DOI: 10.11607/jomi.3617.

23. Rossi F. A Cone beam tomographic evaluation of hard tissue alterations at immediate implants: a clinical prospective study. Int J Periodontics Restorative Dent 2013;33(6):815-823. DOI: 10.11607/prd.1442. 